\title{
Aerosols-cloud microphysics-thermodynamics-turbulence: evaluating supersaturation in a marine stratocumulus cloud
}

\author{
F. Ditas ${ }^{1}$, R. A. Shaw ${ }^{1,2}$, H. Siebert ${ }^{1}$, M. Simmel ${ }^{1}$, B. Wehner ${ }^{1}$, and A. Wiedensohler ${ }^{1}$ \\ ${ }^{1}$ Leibniz Institute for Tropospheric Research (IfT), Permoserstr. 15, 04318 Leipzig, Germany \\ ${ }^{2}$ Department of Physics, Michigan Technological University, Houghton, Michigan, USA \\ Correspondence to: F. Ditas (ditas@tropos.de)
}

Received: 11 October 2011 - Published in Atmos. Chem. Phys. Discuss.: 4 November 2011

Revised: 2 February 2012 - Accepted: 20 February 2012 - Published: 5 March 2012

\begin{abstract}
This work presents a unique combination of aerosol, cloud microphysical, thermodynamic and turbulence variables to characterize supersaturation fluctuations in a turbulent marine stratocumulus (SC) layer. The analysis is based on observations with the helicopter-borne measurement platform ACTOS and a detailed cloud microphysical parcel model following three different approaches: (1) From the comparison of aerosol number size distributions inside and below the SC layer, the number of activated particles is calculated as $435 \pm 87 \mathrm{~cm}^{-3}$ and compares well with the observed median droplet number concentration of $\bar{N}_{\mathrm{d}}=464 \mathrm{~cm}^{-3}$. Furthermore, a $50 \%$ activation diameter of $D_{\mathrm{p} 50} \approx 115 \mathrm{~nm}$ was derived, which was linked to a critical supersaturation $S_{\text {crit }}$ of $0.16 \%$ via Köhler theory. From the shape of the fraction of activated particles, we estimated a standard deviation of supersaturation fluctuations of $\sigma_{S^{\prime}}=0.09 \%$. (2) These estimates are compared to more direct thermodynamic observations at cloud base. Therefore, supersaturation fluctuations $\left(S^{\prime}\right)$ are calculated based on highly-resolved thermodynamic data showing a standard deviation of $S^{\prime}$ ranging within $0.1 \% \leq \sigma_{S^{\prime}} \leq 0.3 \%$. (3) The sensitivity of the supersaturation on observed vertical wind velocity fluctuations is investigated with the help of a detailed cloud microphysical model. These results show highest fluctuations of $S^{\prime}$ with $\sigma_{S^{\prime}}=0.1 \%$ at cloud base and a decreasing $\sigma_{S^{\prime}}$ with increasing liquid water content and droplet number concentration. All three approaches are independent of each other and vary only within a factor of about two.
\end{abstract}

\section{Introduction}

The atmosphere's radiation budget and aerosol particles are linked via (1) the radiative properties of the aerosol particles themselves (direct aerosol effect) and (2) via influencing cloud microphysics (indirect aerosol effect) and, therefore, cloud radiative properties. The first description of the indirect aerosol effect on climate was introduced by Warner and Twomey (1967). Assuming a constant liquid water content (LWC) but increasing number of cloud condensation nuclei $(\mathrm{CCN})$ the same amount of water is distributed to a larger number of smaller droplets (first indirect effect). Later Albrecht (1989) focused on the effect of "polluted" droplet spectra on cloud lifetime and precipitation (second indirect effect, cloud lifetime effect). Since then, it has become clear that there is a range of subtle aerosol-cloud interactions (e.g., Stevens and Feingold, 2009), and quantifying them remains a challenge.

Besides direct measurements of aerosol and cloud droplet populations, the supersaturation field is of great interest because it serves to link the two populations via activation. For example, activation theories have been highly refined to allow high resolution in critical supersaturation to be determined, based on aerosol chemical composition (Wex et al., 2007; Petters and Kreidenweis, 2007). Aerosols do not typically activate in a quiescent background of uniform supersaturation, however, but rather in a highly fluctuating, turbulent supersaturation field. Therefore, some studies have been carried out to estimate the effects of saturation fluctuations on droplet growth (Cooper, 1989; Khvorostyanov and Curry, 1999). Kulmala et al. (1997) pointed out that some droplets are able to grow in on average undersaturated 
conditions. To make matters more complex, the fluctuations do not arise solely from turbulent mixing of temperature and water vapor concentration fields, but also from the mass exchange associated with the activation process itself. Thereby, growing droplets are acting as sinks for the local supersaturation, which furthermore, can vary from droplet to droplet (Srivastava, 1989). Achieving internal consistency between aerosol distributions, cloud droplet distributions, turbulence, and thermodynamic fluctuations is still a significant challenge, and is the context of this work.

In this study, we evaluate the magnitude of supersaturation fluctuations $\left(S^{\prime}\right)$ in a turbulent marine stratocumulus layer over the Baltic Sea. The measurements were obtained with the helicopter-borne platform ACTOS (Airborne Cloud Turbulence Observation System, Siebert et al., 2006); its true air speed of only 15 to $20 \mathrm{~m} \mathrm{~s}^{-1}$ allows us to compare highly resolved and spatially collocated thermodynamic and cloud microphysical properties with microphysical properties of the interstitial aerosol nearby the turbulent cloud layer. Unlike most prior airborne studies, we also measure the nonactivated interstitial aerosol inside an SC to draw conclusions on the activation properties. Within the framework of this paper, we focus on three approaches for characterizing supersaturation fluctuations: (1) aerosol number size distribution inside and outside the stratocumulus cloud and the resulting activation properties as well as a comparison with observed cloud droplet number concentration, (2) water vapor supersaturation at the cloud base derived from highly resolved thermodynamic data, and (3) a sensitivity analysis of the influence of measured vertical velocity fluctuations on the supersaturation field determined with a cloud microphysical parcel model.

\section{Experimental}

This study draws on measurements of marine stratocumulus clouds over the Baltic Sea, obtained on 5 October 2007 during a flight originating from the Kiel-Holtenau airport in Germany ( $\left.54^{\circ} 22^{\prime} 46^{\prime \prime} \mathrm{N}, 10^{\circ} 8^{\prime} 43^{\prime \prime} \mathrm{E}\right)$. ACTOS operated north of the city of Kiel over rural area, the coast line and the Baltic Sea, in the measurement area shown in Fig. 1.

\subsection{Airborne Cloud Turbulence Observation System (ACTOS)}

The helicopter-borne measurement platform ACTOS is equipped with a variety of high resolution sensors for meteorological and turbulence parameters as well as cloud and aerosol microphysical properties. ACTOS is an autonomous platform with its own data acquisition system and power supply. A wireless network uplink to the helicopter ensures online monitoring of the most important parameters during flight. ACTOS is carried by means of a $140 \mathrm{~m}$ long rope beneath a helicopter and operates at a true air speed of 15 to

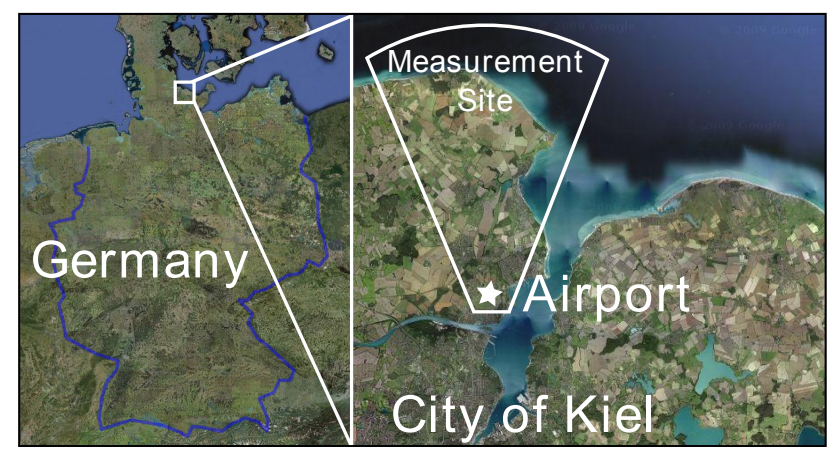

Fig. 1. Measurement site at the airport of Kiel-Holtenau (maps are taken from http://maps.google.de).

$20 \mathrm{~m} \mathrm{~s}^{-1}$. The combination of low true air speed and high sampling frequency results in a spatial resolution on the centimetre scale for standard meteorological parameters. For a detailed description of ACTOS and its instrumentation see Siebert et al. (2006).

\subsection{Aerosol and cloud microphysical instrumentation}

During this campaign, aerosol number size distributions (NSDs) in the size range of $6 \mathrm{~nm}<D_{\mathrm{p}}<2.6 \mu \mathrm{m}$ were recorded by a Scanning Mobility Particle Sizer (SMPS, IfT, Leipzig, Germany) and an Optical Particle Counter (model 1.129, Grimm Aerosol Technik GmbH, Ainring, Germany). Additionally, the total particle number concentration of the interstitial aerosol larger than $D_{\mathrm{p}}=6 \mathrm{~nm}$ was measured by a Condensational Particle Counter with an increased temperature difference between saturator and condensor (CPC 3762, TSI Incorporate, Shoreview, MN, USA). For a detailed description of the aerosol instrumentation, the reader is referred to Wehner et al. (2010). The aerosol inlet consists of a horizontally oriented tube, which is curved $90^{\circ}$ to the mean flow direction. Taking into account aspiration efficiency and losses at the $90^{\circ}$ bend (Baron and Willeke, 2001) particles and cloud droplets larger than $5 \mu \mathrm{m}$ are not able to enter the aerosol measurement system. This ensures exclusive sampling of interstitial particles.

Cloud droplet spectra were measured with the PhaseDoppler Interferometer for Cloud Turbulence (PICT, Chuang et al., 2008). The PICT instrument measures size and speed (in flight direction) of individual droplets between $3 \mu \mathrm{m}<D_{\mathrm{d}}<100 \mu \mathrm{m}$, with no dead time losses and with minimal coincidence sizing errors. Liquid water content (LWC) was measured with the Particle Volume Monitor (PVM, Gerber, 1991). Temperature and humidity measurements at cloud base were performed by an ultra-fast thermometer (UFT) and an infra-red absorption hygrometer, respectively (Siebert et al., 2006). Both sensors are located in the frontal outrigger of the measurement platform. 


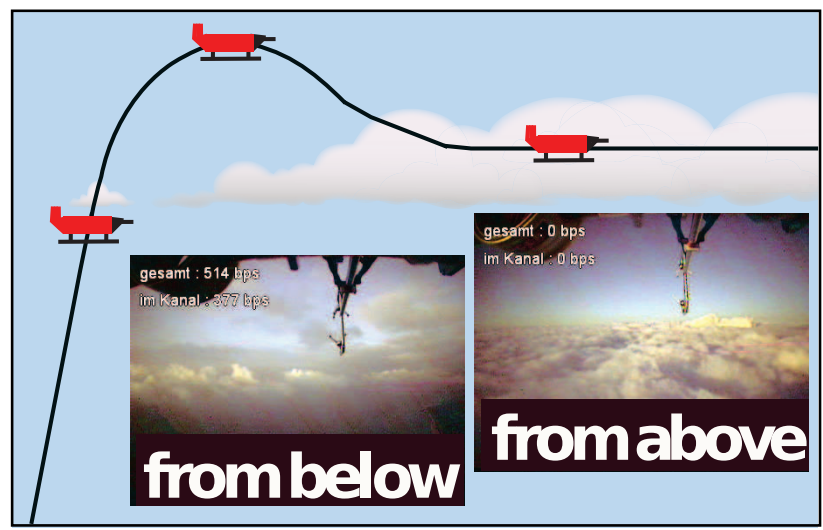

Fig. 2. Scheme of the flight pattern of ACTOS on 5 October 2007. Subfigures show pictures of the observed stratocumulus taken by the on-board camera.

\section{Measurements}

On 5 October, ACTOS performed measurements near and inside a SC layer advected from the Baltic Sea to Northern Germany. After take-off, the flight started with a vertical profile up to approximately $1000 \mathrm{~m}$ above ground level (AGL, all following heights refer to ground level of airport) where ACTOS touched the cloud base of the SC layer. The vertical profile was then continued in cloud free area up to a height of approximately $1550 \mathrm{~m}$. After descending to cloud top height ACTOS was dipped into the SC from above (cf. Fig. 2). Several horizontal flight legs with constant altitude were performed inside the SC layer. A second vertical profile was accomplished about $1 \mathrm{~h}$ after the first one during the descent on the way back to the airport. The complete measurement flight took approximately $1.5 \mathrm{~h}$.

\subsection{Vertical structure}

Figure 3 shows vertical profiles of selected meteorological parameters measured during ascent and descent. The potential temperature $(\theta)$ features a slight increase in the lowermost $1000 \mathrm{~m}$ indicating a stably stratified atmosphere. This is followed by a strong temperature increase until about $1300 \mathrm{~m}$, which belongs to an inversion above the observed stratocumulus. The absolute humidity $(q)$ shows a decrease with height until the altitude of the inversion, differences between ascent and descent are likely due to horizontal inhomogeneities. The wind direction $(d d)$ was north-east to east, its vertical distribution exhibits mainly a change of approximately $30^{\circ}$ during the lowermost $500 \mathrm{~m}$. Within the same height interval, the wind velocity $(U)$ increases by around $5 \mathrm{~m} \mathrm{~s}^{-1}$. Furthermore, abrupt changes are only found at the inversion.

The absence of strong vertical gradients in $d d$ and $U$ below the inversion layer indicates that the SC and the subcloud layer are coupled. The total particle number con-

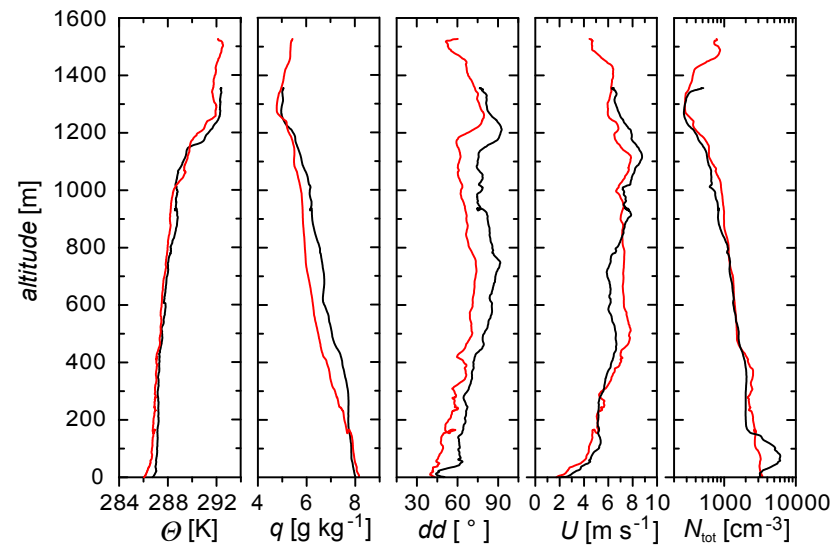

Fig. 3. Vertical profiles of potential temperature $(\Theta)$, absolute humidity $(q)$, wind direction $(d d)$, wind velocity $(U)$ and total particle number concentration ( $\left.N_{\text {tot }}\right)$ recorded during ascent (black lines) and descent (red lines). Note that vertical profiles were performed in cloud free area.

centration $\left(N_{\text {tot }}\right)$ features a continuous decrease from about $3000 \mathrm{~cm}^{-3}$ at the ground to a few hundreds per cubic centimetre at the altitude of the inversion. This is followed by an increase to $N_{\text {tot }} \approx 1000 \mathrm{~cm}^{-3}$ above the inversion. The variability in the lowermost $200 \mathrm{~m}$ is possibly due to ground effects or local pollution. The observed SC layer was located between $1000 \mathrm{~m}$ and $1300 \mathrm{~m}$. Note that for flight safety reasons, the helicopter is not allowed to fly into clouds. Vertical profiles are recorded in cloud free areas during ascents and descents. Due to the forward velocity of the platform, vertical gradients are to some degree influenced by horizontal gradients and displayed vertical profiles may differ from those directly below the cloud layer.

\subsection{Measurements at cloud level}

Figure 4 shows a time series of selected parameters during an in-cloud flight leg. ACTOS penetrated the cloud layer from above and performed an approximately $5 \mathrm{~km}$ long leg at $1250 \pm 15 \mathrm{~m}$. At the beginning, the interstitial particle number concentration $\left(N_{\text {int }}\right)$ increases sharply because ACTOS was dipped into the stratocumulus from above, where $N_{\text {int }}$ is significantly lower (cf. Fig. 3).

Inside the cloud, $N_{\text {int }}$ varies mostly between 1000 and $1300 \mathrm{~cm}^{-3}$, which is higher compared to the value observed for the vertical profile. The difference may be due to horizontal inhomogeneities because vertical profiles were recorded at some distance from the cloud as mentioned above. The LWC ranges mainly between 0.6 and $1.0 \mathrm{~g} \mathrm{~m}^{-3}$, while the vertical wind velocity $(w)$ shows variations within $\pm 1.5 \mathrm{~m} \mathrm{~s}^{-1}$ with a standard deviation of $\sigma_{w}=0.6 \mathrm{~m} \mathrm{~s}^{-1}$ and a mean value close to zero. Strong downdrafts correlate well with sharp decreases in the LWC. In the lowest panel, the time series of the observed mean droplet diameter for $10 \mathrm{~s}$ 


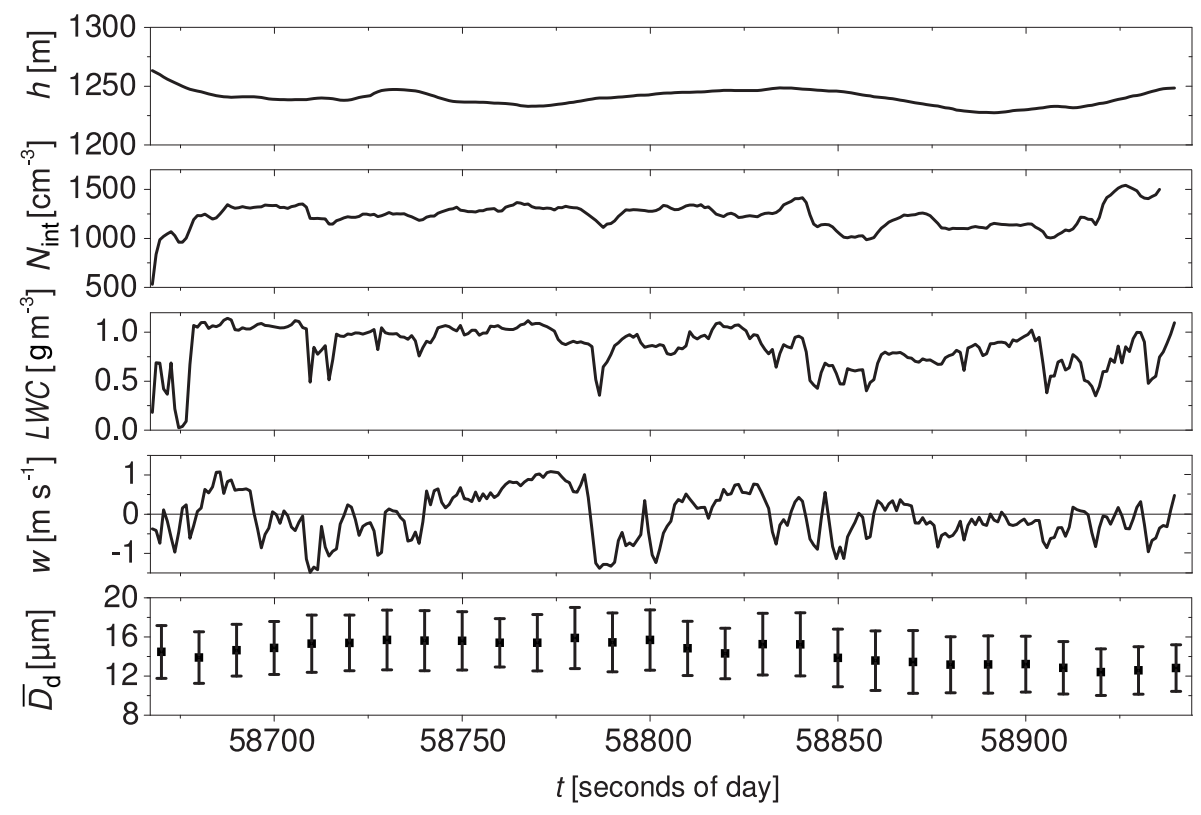

Fig. 4. Time series ( $1 \mathrm{~Hz}$ data) of altitude $(h)$, interstitial particle number concentration $\left(N_{\text {int }}\right)$, liquid water content (LWC), vertical wind velocity $(w)$ and mean droplet diameter $\left(\bar{D}_{\mathrm{d}}\right.$, error bars mark the standard deviation) for $10 \mathrm{~s}$ long intervals during an approximately $5 \mathrm{~km}$ long flight leg inside the SC.

long intervals is shown indicating average diameters between $12 \mu \mathrm{m}$ and $16 \mu \mathrm{m}$ with a nearly constant standard deviation around $2-3 \mu \mathrm{m}$ (error bars). The corresponding mean droplet size distribution to above displayed flight leg is illustrated in Fig. 5. The spectrum shows a broad mono-modal distribution with a maximum concentration at about $D_{\mathrm{d}}=12 \mu \mathrm{m}$. The majority of droplets size between $5 \mu \mathrm{m}<D_{\mathrm{d}}<20 \mu \mathrm{m}$, while median total droplet concentration for this cloud passage averages out at approximately $470 \mathrm{~cm}^{-3}$ with an interquartile spread of $141 \mathrm{~cm}^{-3}$. The median droplet number concentration of all cloud passages is about $\bar{N}_{\mathrm{d}}=464 \mathrm{~cm}^{-3}$ with an interquartile spread of $184 \mathrm{~cm}^{-3}$.

\section{Critical supersaturation}

In this section, three different estimates of the critical supersaturation are presented. The three estimates come from independent measurements, so agreement between them builds confidence in the individual methods and their theoretical foundations. 1. Aerosol and cloud microphysics: aerosol number size distributions inside and outside the cloud are used to compare to cloud droplet number densities as a check, and then to derive an activation diameter and a corresponding critical supersaturation. 2. Thermodynamics: humidity fluctuations are estimated from direct, high resolution measurements of absolute humidity and temperature around the cloud base. 3. Turbulence: a cloud parcel model is utilized to translate observed vertical wind velocity fluctuations into supersaturation fluctuations.

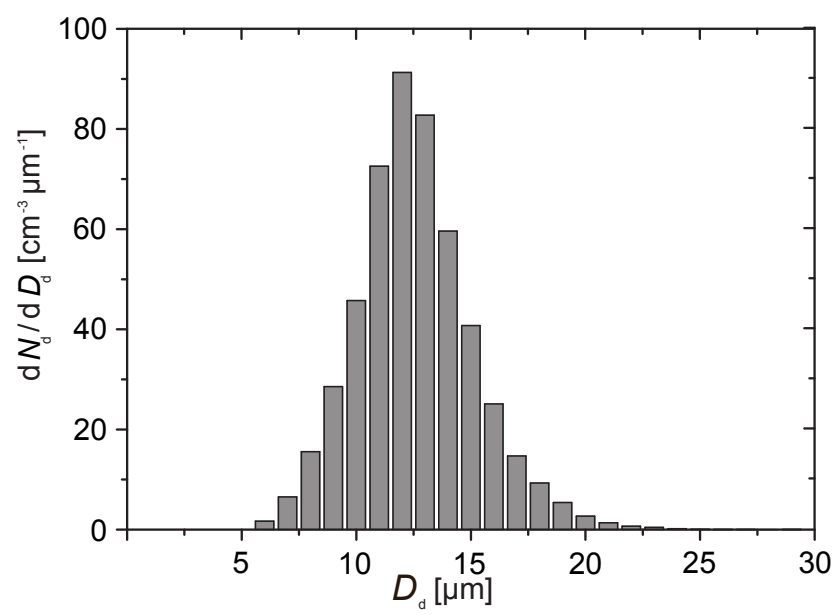

Fig. 5. Average droplet number size distribution corresponding to time period displayed in Fig. 4.

\subsection{Aerosol number size distribution}

Figure 6 shows aerosol number size distributions of the interstitial aerosol (left ordinate) from inside (in-cloud NSDs) and below (sub-cloud NSDs) the stratocumulus. Sub-cloud NSDs were measured during the ascent and descent below the cloud, while in-cloud ones belong to horizontal flight legs at about $1250 \mathrm{~m}$. The sub-cloud NSDs exhibit a bimodal distribution which is typical for marine aerosol. However, incloud NSDs consist mainly of one broad mode. All NSDs 


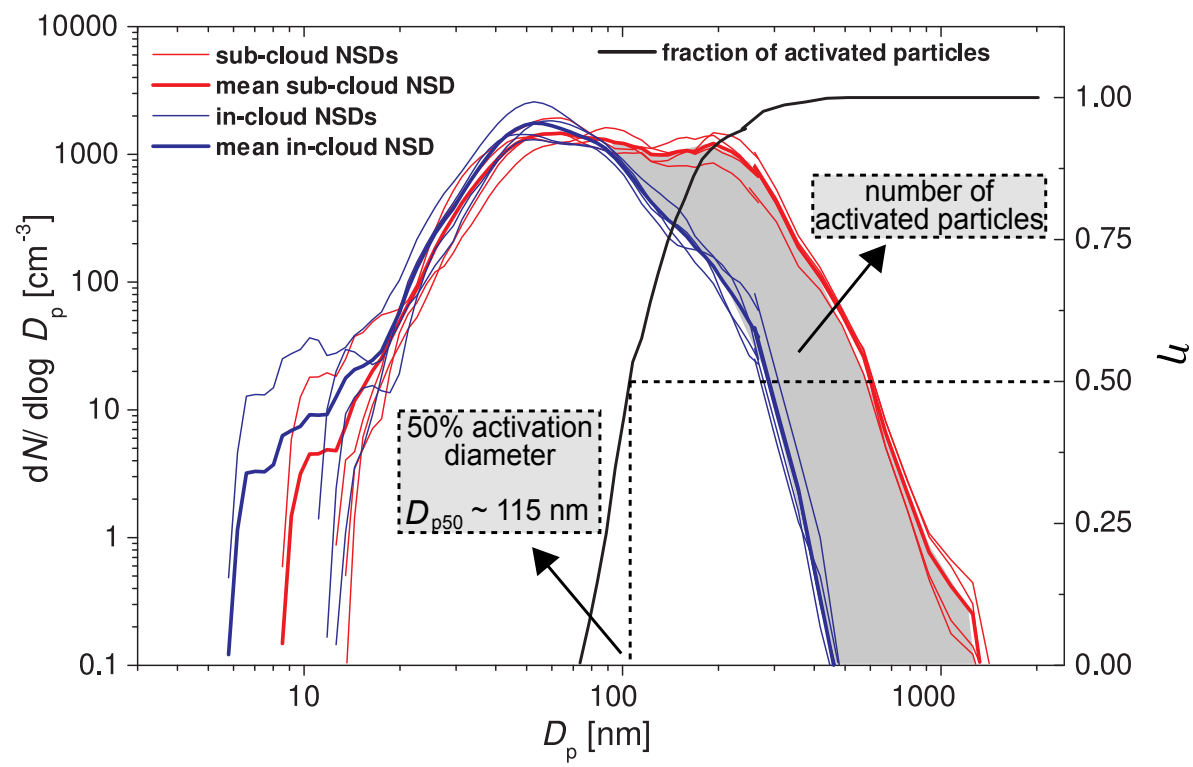

Fig. 6. Aerosol number size distributions of the interstitial aerosol (left ordinate) inside (blue lines) and below (red lines) the observed stratocumulus layer and number fraction of activated particles (right ordinate).

feature a similar Aitken mode $\left(20 \mathrm{~nm}<D_{\mathrm{p}}<70 \mathrm{~nm}\right)$, implying that sub-cloud and in-cloud aerosols originate from the same air mass.

Comparing the in-cloud and sub-cloud NSDs, significant differences are obvious. For particles larger than $D_{\mathrm{p}}=70 \mathrm{~nm}$, a spread between in-cloud and sub-cloud NSDs occurs that can be explained by activation of aerosols to cloud droplets. The shaded area in Fig. 6 illustrates the number of activated particles $N_{\text {act }}$. We derive $N_{\text {act }}$ by integrating the sub-cloud and in-cloud NSDs for particles between $80 \mathrm{~nm}<D_{\mathrm{p}}<2600 \mathrm{~nm}$ as follows:

$$
\begin{aligned}
N_{\mathrm{act}}= & \int_{D_{\mathrm{p}}=80 \mathrm{~nm}}^{D_{\mathrm{p}}=2600 \mathrm{~nm}} \mathrm{NSD}_{\text {subcloud }} \mathrm{d} D_{\mathrm{p}} \\
& -\int_{D_{\mathrm{p}}=80 \mathrm{~nm}}^{D_{\mathrm{p}}=2600 \mathrm{~nm}} \mathrm{NSD}_{\text {cloud }} \mathrm{d} D_{\mathrm{p}} .
\end{aligned}
$$

In our case, the difference is about $435 \pm 87 \mathrm{~cm}^{-3}$, which agrees remarkably well with the above introduced median droplet concentration of $\bar{N}_{\mathrm{d}}=464 \mathrm{~cm}^{-3}$. This consistency between aerosol and cloud microphysical measurements provides encouragement to further investigate the activation process that links the two.

In order to quantify an activation diameter, we calculate the fraction of activated particles $\eta$ with the help of the mean in-cloud and sub-cloud NSDs $\left(\overline{\mathrm{NSD}}_{\text {cloud }}\left(D_{\mathrm{p}}\right)\right.$ and $\overline{\mathrm{NSD}}_{\text {subcloud }}\left(D_{\mathrm{p}}\right)$, respectively) as follows:

$\eta\left(D_{\mathrm{p}}\right)=1-\frac{\overline{\operatorname{NSD}}_{\text {cloud }}\left(D_{\mathrm{p}}\right)}{\overline{\operatorname{NSD}}_{\text {subcloud }}\left(D_{\mathrm{p}}\right)}$.
Figure 6 shows $\eta$ (right ordinate), which features a steep increase for particles in the size range of $80 \mathrm{~nm}<D_{\mathrm{p}}<150 \mathrm{~nm}$. For larger particle sizes, $\eta$ approaches unity. From $\eta=0.5$, a $50 \%$-activation diameter of $D_{\mathrm{p} 50} \approx 115 \mathrm{~nm}$ can be derived (cf. Fig. 6). With the help of Köhler theory (Köhler, 1936) and an assumption about the chemical composition, $D_{\mathrm{p} 50}$ can be related to a critical supersaturation. Since ACTOS is not equipped with instruments to analyze the aerosol chemical composition, we have to make an assumption for the hygroscopicity. Among others, Neusüß et al. (2002) investigated the chemical composition of Central European aerosol and found a dominating mass fraction of ammonium sulfate. To make a first guess we assume a pure ammonium sulfate particle containing an insoluble core. Chemical analysis during LACE 98 support this (Busch et al., 2002), furthermore, the same authors found an overall mean of the water-solube volume fraction of $\epsilon=0.6$, additionally they also found a class of highly soluble particles with $\epsilon=0.85$. Therefore, we use an ammonium sulfate particle with a dry diameter of $D_{\mathrm{p}}=D_{\mathrm{p} 50}=115 \mathrm{~nm}$ and a soluble fraction of $\epsilon=0.7$ and calculate that a minimum supersaturation of $S_{\text {crit }}=0.16 \%$ is required to activate the particle as cloud droplet.

In the next step, we concentrate again on the fraction of activated particles $(\eta)$. Taking into account that a small fraction of particles with a diameter of $D_{\mathrm{p}}=80 \mathrm{~nm}$ and smaller are activated, a critical supersaturation of $S_{\text {crit }}=0.28 \%$ is necessary. If we had a single updraft velocity and perfectly homogeneous aerosol composition and concentration, we should see a perfect step function for $\eta$. Instead, we see an error function (erf) like behaviour. In order to relate this roll-off to the distribution of critical supersaturation, 


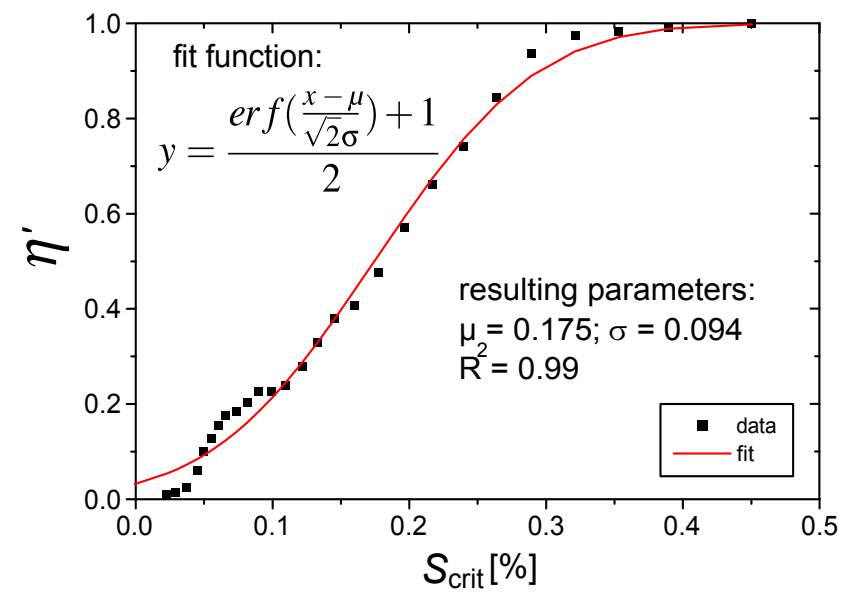

Fig. 7. Activated fraction $\eta^{\prime}$ as function of critical supersaturation $S_{\text {crit }}$ (squares). Red line denotes a fitted error function.

we convert $\eta\left(D_{\mathrm{p}}\right)$ to a function of critical supersaturation by calculating the critical supersaturation (with the same chemical parameters as above) for every $D_{\mathrm{p}}$ via Köhler theory. Figure 7 illustrates the resulting activated fraction $\eta^{\prime}\left(S_{\text {crit }}\right)$ (black squares), which exhibits a similar error function like behaviour as $\eta\left(D_{\mathrm{p}}\right)$ in Fig. 6. For clarity, here, the activated fraction as a function of critical supersaturation is defined as $\eta^{\prime}\left(S_{\text {crit }}\right)=1-\eta\left(S_{\text {crit }}\right)$ so as to show an increase with critical supersaturation, although the shape parameters obtained from the curve are independent of this choice.

This gives us the opportunity to estimate the mean critical supersaturation and its standard deviation by applying a least squares fit to $\eta^{\prime}$ with the function $y=\frac{\operatorname{erf}((x-\mu) /(\sqrt{2} \sigma))+1}{2}$ using the mean and standard deviation $(\mu, \sigma)$ as free parameters. The fit function is plotted in Fig. 7 (red line), the resulting $\mu=0.175 \%$ agrees well with the above derived $S_{\text {crit }}\left(D_{\mathrm{p} 50}\right)$, while the standard deviation calculates to $\sigma_{S^{\prime}}=0.09 \%$.

\subsection{Absolute humidity and temperature fluctuations}

We now compare these estimates with more direct thermodynamic observations leading to relative humidity (RH) at cloud base. During the first ascent, ACTOS touched the cloud base at about $1000 \mathrm{~m}$ above ground level. Performing accurate measurements of $\mathrm{RH}$ or supersaturation $(S)$ in the presence of cloud droplets is still a difficult task, but we make an attempt here in order to compare with the other methods for evaluating $\sigma_{S^{\prime}}$. We derived RH from collocated temperature and absolute humidity measurements with an ultrafast thermometer (UFT) and infra-red absorption hygrometer both with a temporal resolution of $100 \mathrm{~Hz}$. The longitudinal separation between both sensors was considered before combining the two measurements. The absolute accuracy of our humidity estimates is on the order of a few percent. Observed

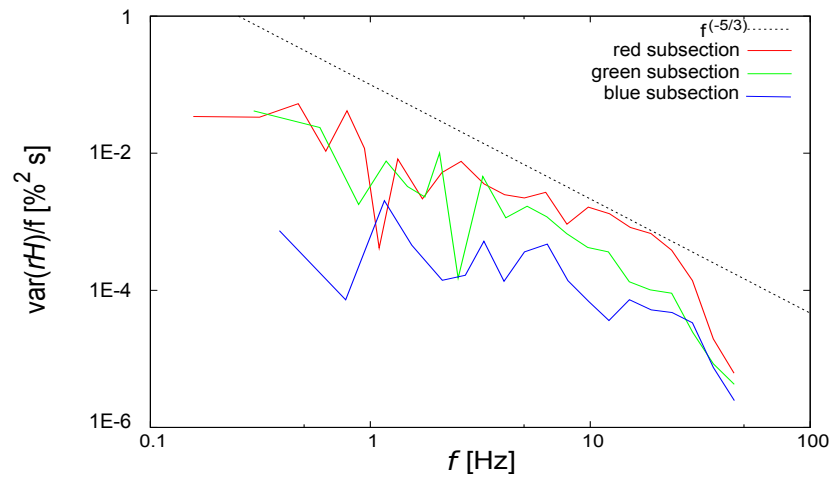

Fig. 8. Power spectral density of three different subsections (green, blue and red lines) during cloud penetration of ACTOS at cloud base. Dashed line refers to the $-5 / 3$ slope for the inertial subrange scaling.

fluctuations, however, are interpreted as real and afterwards termed saturation fluctuations $\left(S^{\prime}\right)$.

For quality assurance of the resulting time series of RH, we applied power spectral analysis. Figure 8 shows power spectra of three different subsets during the cloud penetration of ACTOS, which will be analysed concerning supersaturation later on. All spectra feature a large scattering due to poor sampling statistics of the short subsections. Regardless of the scatter, all spectra show roughly a mean slope of $-5 / 3$, which implies inertial subrange scaling. This implies that the fluctuations are a result of real turbulence and not noise, which would result in a flat and horizontal spectrum. Strong deviations from the $-5 / 3$ slope could also be a result of scattering effects of single cloud droplets in the measuring volume of the infra-red absorption hygrometer, which was also not observed.

Figure 9 displays linearly detrended $S^{\prime}$ and LWC as function of the altitude. The saturation fluctuations are divided into three subsections according to different mean LWC values. The first subsection (green line) refers to zero LWC, the blue line belongs to a LWC slightly above the noise level and the last subsection (red line) references a mean LWC $\sim 0.02 \mathrm{~g} \mathrm{~m}^{-3}$. For these different subrecords, the standard deviation of the supersaturation fluctuations $\left(\sigma_{S^{\prime}}\right)$ is calculated. The green subsection which is located a few meters below the cloud base features a standard deviation of $0.2 \%$ whereas the peak to peak $(\mathrm{p} 2 \mathrm{p})$ values reach $1.2 \%$. In the blue subsection, only calm fluctuations occur with $\sigma_{S^{\prime}}=0.1 \%$ which range within $0.5 \%$. The strongest fluctuations appear in the red subsection with a mean LWC of about $0.02 \mathrm{~g} \mathrm{~m}^{-3}$. The standard deviation achieves $0.3 \%$ and the fluctuations range within $1.5 \%$. All together these estimates of saturation fluctuations at standard deviations within a few tenth of percent agree well with the above derived values of the critical supersaturation but local values are expected to be higher. 


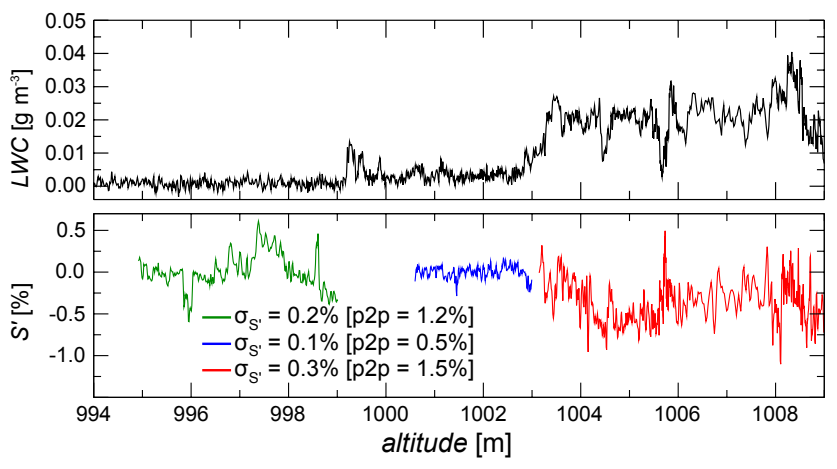

Fig. 9. Liquid water content (LWC) and linearly detrended saturation fluctuations $\left(S^{\prime}\right)$ as function of the altitude during the first ascent when ACTOS touched the cloud base of the SC layer.

\subsection{Vertical velocity fluctuations}

Here, we investigate the influence of turbulent vertical wind fluctuations on the supersaturation field with the help of the detailed cloud microphysical parcel model of Simmel and Wurzler (2006). Essentially, we wish to evaluate the range of supersaturation fluctuations that can be achieved for realistic fluctuations in vertical velocity occurring during the activation and condensation growth of cloud droplets near cloud base, assuming uniform aerosol number concentration. In this study, the model is used with a moving size-bin approach to avoid numerical diffusion along the mass axis. Furthermore, we focus on pure condensational droplet growth ignoring collision/coalescence and entrainment.

During the initialization of the cloud microphysical model, an air parcel is lifted by a constant updraft $w_{\text {init }}$ until a specified altitude or average liquid water content is reached. The air parcel starts to rise just beneath the cloud base observed by ACTOS. The initial conditions are characterised by a static pressure of $p=905 \mathrm{hPa}$, a temperature of $T=278.9 \mathrm{~K}$ and a relative humidity of $\mathrm{RH}=96 \%$ resulting in a model cloud base at $1065 \mathrm{~m}$. The initial aerosol number size distribution is represented by $4 \log$-normal modes, which were fitted to the observed mean aerosol number size distribution measured below the cloud base of the stratocumulus. After the initialisation, the model is driven by detrended vertical wind velocity fluctuations $\left(w^{\prime}\right)$ recorded during a flight leg inside the stratocumulus layer.

Basically, with this approach we compare two different reference frames. We use Eulerian measurements to drive a detailed cloud microphysical parcel model in a Lagrangian reference frame. In principle, the conversion of measured time series of wind fluctuations into spatially resolved fluctuations is possible by using Taylors frozen flow hypothesis (Taylor, 1938). Furthermore, for homogeneous turbulence the probability density functions (pdf) of "one-point one-time" velocity fluctuations (Eulerian reference frame) can be taken as equivalent to Lagrangian velocity fluctua- tions (see e.g., Pope, 2000, p. 483). Instead of multiplying the measured time series $w(t)$ with the true airspeed of the measurement platform to get $w(x)$ (Taylors frozen flow hypothesis) we considered the ratio of two different time scales: (i) the time $\mathcal{T}$ ACTOS needs to pass an eddy of typical size $L$ and (ii) the typical eddy turn-over time $\tau_{\text {eddy }}$, which describes the typical residence time of an air parcel in the same eddy. The first time scale can be estimated by integrating the autocorrelation function $\rho_{w}(\tau)$. In practise, $\rho_{w}(\tau)$ is assumed to exhibit an exponential shape and $\mathcal{T}$ is taken as the time where $\rho_{w}(\mathcal{T})=1 /$ e. From the measurements, we estimate $\mathcal{T} \approx 2.6 \mathrm{~s}$. The second time scale can be estimated by $\tau_{\text {eddy }} \sim L / \sigma_{w}$, where $L=U \cdot \mathcal{T} \approx 20 \mathrm{~m} \mathrm{~s}^{-1} \cdot 2.6 \mathrm{~s} \approx 50 \mathrm{~m}$ is the integral length scale ( $U$ is the true airspeed of ACTOS). With a standard deviation $\sigma_{w} \approx 0.6 \mathrm{~m} \mathrm{~s}^{-1}$, we get $\tau_{\text {eddy }} \approx 80 \mathrm{~s}$. That is, if ACTOS samples one eddy in the time $\mathcal{T}$, an air parcel spends the time $\tau_{\text {eddy }}$ in this eddy and we have to stretch the simulation time by a factor of $\tau_{\text {eddy }} / \mathcal{T} \approx U / \sigma_{w} \sim 30$. Although, the observed vertical wind velocity fluctuations are detrended, subrecords contain longer periods of up- and downdrafts leading to a vertical shift of the air parcel. Therefore, stretching the simulation time increases the vertical displacement. Note that this is an order of magnitude estimate and with a factor of 30 the vertical shift of an air parcel would be about $\pm 300 \mathrm{~m}$, exceeding the thickness of the observed SC, we want to compare with. For this reason, in our simulations, we used a factor of 10 to limit this shift to $\pm 100 \mathrm{~m}$. Furthermore, sensitivity estimates for different stretching factors do not show a strong influence on the resulting $\sigma_{S^{\prime}}$. The factor is realized by using single data points of the $100 \mathrm{~Hz}$ resolution time series with a model time step of $0.1 \mathrm{~s}$.

We have performed two types of model runs that allow us to initiate the vertical velocity fluctuations just after or during the activation process. This is achieved through two scenarios for initializing the model: (a) lifting the air parcel with a constant updraft velocity $w_{\text {init }}$ until a certain $\overline{\mathrm{LWC}}$ is reached and (b) lifting the air parcel with a constant velocity to a certain altitude $(h)$ close to the cloud base. In concept (a), the vertical wind fluctuations are switched on when the air parcel has already entered the cloud layer. Instead, concept (b) allows us to investigate the influence of the wind fluctuations on the supersaturation field directly at the condensation level. In this case, the subsequent wind fluctuations and the resulting vertical displacement of the air parcel lead to activation and deactivation of aerosols and cloud droplets, respectively.

Figure 10 shows time series of the observed vertical wind velocity and the resulting modelled supersaturation after the initialization of the cloud microphysical model following concept (a) with an initial wind speed of $w_{\text {init }}=0.1 \mathrm{~m} \mathrm{~s}^{-1}$ and $\overline{\mathrm{LWC}}=0.2 \mathrm{~g} \mathrm{~m}^{-3}$. The figure displays the fluctuations in the supersaturation field arising from $w^{\prime}$. In Table 1 the initial parameters and results of six model runs are presented. The model runs A1, A2 and A3 follow the initializing concept (a). Within A1 and A2 the air parcel is lifted until 

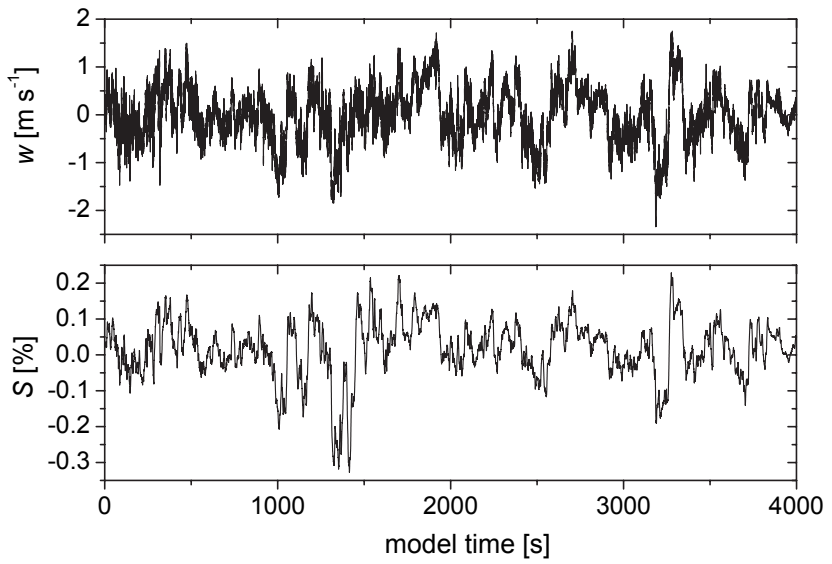

Fig. 10. Time series of vertical wind velocity (upper panel) driving the cloud parcel model and modelled supersaturation (lower panel) corresponding to during model run A1.

Table 1. Initial vertical wind velocity ( $\left.w_{\text {init }}\right)$, mean height $(h)$, mean liquid water content $(\overline{\mathrm{LWC}})$, standard deviation $\left(\sigma_{\mathrm{S}^{\prime}}\right)$ and peak to peak values $(\mathrm{p} 2 \mathrm{p})$ of the supersaturation fluctuations $\left(S^{\prime}\right)$ for six model runs. All model runs feature a model cloud base of $1065 \mathrm{~m}$

\begin{tabular}{cccccc}
\hline $\begin{array}{c}\text { model } \\
\text { run }\end{array}$ & $\begin{array}{c}w_{\text {init }} \\
{\left[\mathrm{m} \mathrm{s}^{-1}\right]}\end{array}$ & $\begin{array}{c}h \\
{[\mathrm{~m}]}\end{array}$ & $\begin{array}{c}\mathrm{LWC} \\
{\left[\mathrm{g} \mathrm{m}^{-3}\right]}\end{array}$ & $\sigma_{\mathrm{S}^{\prime}}[\%]$ & $\mathrm{p} 2 \mathrm{p}[\%]$ \\
\hline A1 & 0.1 & 1200 & 0.2 & 0.08 & 0.56 \\
$\mathrm{~A} 2$ & 0.4 & 1200 & 0.2 & 0.07 & 0.49 \\
$\mathrm{~A} 3$ & 1.0 & 1800 & 0.8 & 0.03 & 0.19 \\
$\mathrm{~B} 1$ & - & 1035 & - & 0.1 & 0.57 \\
$\mathrm{~B} 2$ & - & 1040 & - & 0.09 & 0.58 \\
$\mathrm{~B} 3$ & - & 1045 & - & 0.07 & 0.45 \\
\hline
\end{tabular}

$\overline{\mathrm{LWC}}=0.2 \mathrm{~g} \mathrm{~m}^{-3}$, which corresponds to an altitude of about $1200 \mathrm{~m}$. Afterwards, the model is driven by the observed vertical wind fluctuations causing supersaturation fluctuations with a standard deviation of 0.08 and $0.07 \%$, respectively and peak to peak values (p2p) up to $0.56 \%$. In A3, the parcel was lifted up to an altitude of $1800 \mathrm{~m}$ and features calm supersaturation fluctuations with a standard deviation of $0.03 \%$ at a range of only $0.19 \%$. B 1 to $\mathrm{B} 3$ follow the initialization scheme (b). In this case, the air parcel is lifted into altitudes between 1035 and $1045 \mathrm{~m}$, which is below the cloud base. Furthermore, the initial vertical wind velocity does not influence the activation process and, therefore, is of marginal importance. Due to the vertical displacement resulting from driving the model by $w$ the air parcel is lifted up and down and enters the cloud several times. The results for B1, B2 and B3 correspond to subsections of the model runs longer than 500 model seconds where the air parcel was located between 1065 and $1100 \mathrm{~m}$ to focus only on the supersaturation field at the cloud base. B1 and B2 exhibit the highest coupling of $w^{\prime}$ and $S^{\prime}$ with standard deviations up to $0.1 \%$ and maximum peak to peak values of $0.58 \%$.

\section{Summary and discussion}

This study presents a unique combination of cloud and aerosol microphysical, thermodynamic, and turbulence variables measured at high temporal and spatial resolution in a stratocumulus cloud. These measurements and results from a cloud microphysical parcel model have allowed three independent approaches for characterizing supersaturation magnitudes and fluctuations. First, from the measurements of the interstitial aerosol below cloud base and inside the cloud, we were able to calculate the fraction of activated particles, which agrees remarkably well with the observed median cloud droplet number concentration. We then derived a $50 \%$ activation diameter of $115 \mathrm{~nm}$ which can be related to a critical supersaturation of $0.16 \%$ via Köhler theory. The roll-off of the fraction of activated aerosols allows us to estimate the range of supersaturation fluctuations, assuming all aerosols have identical composition. With the help of fitting an error function to the fraction of activated particles we find $\sigma_{S^{\prime}} \approx 0.09 \%$. The highly resolved turbulence measurements give insights into the fluctuation of the supersaturation at cloud base. Calculated supersaturation fluctuations vary with a standard deviation ranging from $0.1 \leq \sigma_{S^{\prime}} \leq 0.3 \%$, which agrees well with the above derived critical supersaturation. Peak to peak values indicated a fluctuation range within $1.5 \%$. With the help of the cloud parcel model we analysed the sensitivity of the supersaturation to observed vertical wind fluctuations inside the stratocumulus layer. We found the highest supersaturation fluctuations for model runs at cloud base $\left(\sigma_{S^{\prime}}=0.1 \%\right.$ and peak to peak values of $0.58 \%$ ). This behaviour can be interpreted through the phase relaxation time, defined approximately as: $\tau_{\mathrm{p}}=\left(2 \pi \cdot d \cdot \bar{D}_{\mathrm{d}} \cdot \bar{N}_{\mathrm{d}}\right)^{-1}$ (e.g., Rogers and Yau, 1989; Khvorostyanov and Curry, 1999; Austin et al., 1985), where $d$ is the water vapor diffusivity $\left(\approx 2.2 \times 10^{-5} \mathrm{~m}^{2} \mathrm{~s}^{-1}\right.$, e.g., Houghton, 1985), and $\bar{D}_{\mathrm{d}}$ and $\bar{N}_{\mathrm{d}}$ are the mean droplet diameter and droplet number concentration, respectively. The phase relaxation time is a measure of how fast the water vapor is redistributed between vapor and condensed phases after a rapid change in $S$. Alternately, it is the time scale for approaching a quasi-steady-state supersaturation for a given steady vertical velocity. Considering model run A3 (cf. Table 1), which features a very high droplet concentration of $\bar{N}_{\mathrm{d}} \sim 640 \mathrm{~cm}^{-3}$ and a mean droplet diameter of $\bar{D}_{\mathrm{d}}=14 \mu \mathrm{m}$, this leads to $\tau_{\mathrm{p}} \approx 0.8 \mathrm{~s}$. That is, for such a small phase relaxation time water vapor condenses comparably fast onto the existing droplets, resulting in a strong damping effect and hence very calm fluctuations. Instead, for A1 with $\bar{D}_{\mathrm{d}}=7 \mu \mathrm{m}$ and $\bar{N}_{\mathrm{d}}=500 \mathrm{~cm}^{-3}$ the phase relaxation time is roughly doubled to $\tau_{\mathrm{p}} \approx 2 \mathrm{~s}$, which explains the increase in $\sigma_{S^{\prime}}$ compared to A3. Finally, in the model runs with initialization scheme (b) droplet diameter and concentration are highly variable. During activation and deactivation, $N_{\mathrm{d}}$ changes from zero to a few hundred and vice versa, while the maximum $D_{\mathrm{d}}$ is on the order of $5 \mu \mathrm{m}$. Nevertheless, 
assuming, e.g., $\bar{D}_{\mathrm{d}} \leq 5 \mu \mathrm{m}$ and $\bar{N}_{\mathrm{d}} \leq 150 \mathrm{~cm}^{-3}$, this yields a large $\tau_{\mathrm{p}} \geq 10 \mathrm{~s}$. Hence, the above mentioned damping effect is weak and rapid changes in $w$ result in more intense fluctuations in $S$.

Within the framework of this work we did not consider radiative effects on the equilibrium supersaturation $\left(S_{\text {eq }}\right)$ arising from radiative cooling or heating of the cloud droplets. Marquis and Harrington (2005) pointed out that radiative heating and cooling rates for cloud droplets can vary by 2 to $-15 \mathrm{~K} \mathrm{~h}^{-1}$, depending on radiative fluxes, droplet diameter and droplet location with reference to cloud top and cloud base. Since the reported measurement flight was conducted between 16:30 and 17:45 CET strong shortwave heating can be neglected. Furthermore, longwave forcing can be neglected because the majority of our observed droplets have sizes between 5 and $20 \mu \mathrm{m}$ in diameter. For droplets in this size range the equilibrium supersaturation in the uppermost $50 \mathrm{~m}$ of a stratocumulus cloud can be changed by values on the order of $S_{\mathrm{eq}}= \pm 0.01 \%$ (Marquis and Harrington, 2005, Fig. 6), which is less than $10 \%$ of the estimated variability from our measurements.

Here, we have considered the range of supersaturation fluctuations in a stratocumulus cloud. The question of maximum possible supersaturation fluctuations, or the detailed distribution of supersaturation during cloud activation remains to be fully answered. Ultimately, supersaturation is the result of combined fluctuations of absolute humidity $(q)$ and temperature $(T)$, all of which are closely coupled to the condensed phase through the phase relaxation time. One possibility to estimate a maximum possible supersaturation is, therefore, the investigation of joint probability density functions of $T$ and $q(\operatorname{PDF}(T, q))$, which is the focus of future efforts with ACTOS. It should be evident even from this first effort, however, that variability of the supersaturation field is of great relevance when considering the activation of aerosols.

Acknowledgements. The authors thank enviscope GmbH and Rotorflug $\mathrm{GmbH}$ for technical support during the measurement campaign. RAS acknowledges support from the A. v. Humboldt Foundation and from US National Science Foundation grant AGS-1026123.

Edited by: M. Krämer

\section{References}

Albrecht, B.: Aerosols, cloud microphysics, and fractional cloudiness, Science, 245, 1227-1230, 1989.

Austin, P. H., Baker, M. B., Blyth, A. M., and Jensen, J. B.: Smallscale variability in warm continental cumulus clouds, J. Atmos. Sci., 42, 1123-1138, 1985.

Baron, P. and Willeke, K.: Aerosol Measurement, New York, USA, John Wiley \& Sons, 2001.

Busch, B., Kandler, K., Schütz, L., and Neusüß, C.: Hygroscopic properties and water-soluble volume fraction of atmospheric par- ticles in the diameter range from $50 \mathrm{~nm}$ to $3.8 \mu \mathrm{m}$ during LACE 98, J. Geophys. Res., 107, 8119, doi:10.1029/2000JD000228, 2002.

Chuang, P., Saw, E., Small, J., Shaw, R., Sipperley, C., Payne, G., and Bachalo, W.: Airborne phase doppler interferometry for cloud microphysical measurements, Aerosol Sci. Tech., 42, 685703, 2008.

Cooper, W.: Effects of variable droplet growth histories on droplet size distributions. Part I: Theory, J. Atmos. Sci., 46, 1301-1311, 1989.

Gerber, H.: Direct measurement of suspended particulate volume concentration and far-infrared extinction coefficient with a laserdiffraction instrument, Appl. Optics, 30, 4824-4831, 1991.

Houghton, H.: Physical meteorology, Cambridge, US-MA: The MIT Press, 1985.

Khvorostyanov, V. I. and Curry, J. A.: Toward the theory of stochastic condensation in clouds. Part I: A general kinetic equation, J. Atmos. Sci., 56, 3985-3996, 1999.

Köhler, H.: The nucleus in and the growth of hygroscopic droplets, T. Faraday Soc., 32, 1152-1161, 1936.

Kulmala, M., Rannik, Ü., Zapadinsky, E., and Clement, C.: The effect of saturation fluctuations on droplet growth, J. Aerosol Sci., 28, 1395-1409, 1997.

Marquis, J. and Harrington, J. Y.: Radiative influences on drop and cloud condensation nuclei equilibrium in stratocumulus, J. Geophys. Res., 110, D10205, doi:10.1029/2004JD005401, 2005.

Neusüß, C., Wex, H., Birmili, W., Wiedensohler, A., Koziar, C., Busch, B., Brüggemann, E., Gnauk, T., Ebert, M., and Covert, D.: Characterization and parameterization of atmospheric particle number-, mass-, and chemical-size distributions in Central Europe during LACE 98 and MINT, J. Geophys. Res., 107, 8127, doi:10.1029/2001JD000514, 2002.

Petters, M. D. and Kreidenweis, S. M.: A single parameter representation of hygroscopic growth and cloud condensation nucleus activity, Atmos. Chem. Phys., 7, 1961-1971, doi:10.5194/acp-71961-2007, 2007.

Pope, S.: Turbulent Flows, Cambridge, UK, Cambridge Univ. Pr., 2000.

Rogers, R. R. and Yau, M. K.: A Short Course in Cloud Physics, 3 edn., International Series in Natural Philosophy, Oxford, UK, Butterworth Heinemann, 1989.

Siebert, H., Franke, H., Lehmann, K., Maser, R., Saw, E. W., Schell, D., Shaw, R. A., and Wendisch, M.: Probing finescale dynamics and microphysics of clouds with helicopterborne measurements, B. Am. Meteorol. Soc., 87, 1727-1738, doi:10.1175/BAMS-87-12-1727, 2006.

Simmel, M. and Wurzler, S.: Condensation and activation in sectional cloud microphysical models, Atmos. Res., 80, 218-236, doi:10.1016/j.atmosres.2005.08.002, 2006.

Srivastava, R.: Growth of cloud drops by condensation: a criticism of currently accepted theory and a new approach., J. Atmos. Sci., 46, 869-887, 1989.

Stevens, B. and Feingold, G.: Untangling aerosol effects on clouds and precipitation in a buffered system, Nature, 461, 607-613, doi:10.1038/nature08281, 2009.

Taylor, G. I.: The spectrum of turbulence, Proc. R. Soc. London Ser. A, 164, 476-490, 1938.

Warner, J. and Twomey, S.: The production of cloud nuclei by cane fires and the effect on cloud droplet concentration, J. Atmos. Sci., 
24, 704-706, 1967.

Wehner, B., Siebert, H., Ansmann, A., Ditas, F., Seifert, P., Stratmann, F., Wiedensohler, A., Apituley, A., Shaw, R. A., Manninen, H. E., and Kulmala, M.: Observations of turbulence-induced new particle formation in the residual layer, Atmos. Chem. Phys., 10, 4319-4330, doi:10.5194/acp-10-4319-2010, 2010.
Wex, H., Hennig, T., Salma, I., Ocskay, R., Kiselev, A., Henning, S., Massling, A., Wiedensohler, A., and Stratmann, F.: Hygroscopic growth and measured and modeled critical super-saturations of an atmospheric HULIS sample, Geophys. Res. Lett., 34, L02818, doi:10.1029/2006GL028260, 2007. 